\title{
Ex Vivo-expanded Autologous T Cells IMA101
}

National Cancer Institute

\section{Source}

National Cancer Institute. Ex Vivo-expanded Autologous T Cells IMA101. NCI Thesaurus.

Code C131305.

A preparation of autologous cytotoxic T-lymphocytes, specifically recognizing certain tumor-associated antigens (TAAs), with potential antineoplastic activity. The endogenous T-cells are isolated, expanded ex vivo, and reintroduced back into the patient. Upon administration, the ex vivo-expanded autologous T-cells IMA101 target and kill tumor cells. The T-cells are analyzed beforehand for their ability to specifically recognize certain TAAs, based on a proprietary antigen warehouse. 